\title{
Nurses' Knowledge, Attitude and Practice of Oral Care for Intensive Care Unit Patients
}

\author{
Sara Mohamed Ibrahim1, Amal Mohamed Mudawi2*, Osama Omer ${ }^{3}$ \\ ${ }^{1}$ Department of Dental Public Health, Faculty of Dentistry, Al-Neelain University, Khartoum, Sudan \\ ${ }^{2}$ Department of Prevention and Community Dentistry, Faculty of Dentistry, University of Khartoum, Khartoum, \\ Sudan \\ ${ }^{3}$ Department of Restorative Dentistry, Dublin Dental University Hospital, University of Dublin, Dublin, Ireland \\ Email: sara saraibrahim@yahoo.co.uk, amudawi63@hotmail.com, osama.omer@dental.tcd.ie
}

Received 12 June 2015; accepted 12 July 2015; published 15 July 2015

Copyright (C) 2015 by authors and Scientific Research Publishing Inc.

This work is licensed under the Creative Commons Attribution International License (CC BY). http://creativecommons.org/licenses/by/4.0/

(c) (i) Open Access

\section{Abstract}

The aim of this study was to describe the intensive care unit (ICU) nurses' knowledge, attitude, and practice of mouth care for their patients. This is a cross sectional hospital based study. A total of 154 ICU nurses were randomly selected from seven governmental hospitals in Khartoum state and were invited to take part in this study. $97.4 \%$ of ICU nurses had high knowledge of the importance of mouth care for ICU patients and similarly for the priority of mouth care. However, only $20 \%$ of nurses were found to apply good practice. $64.5 \%$ of the nurses received training in mouth care provision, and $(81 \%)$ indicated that further training would be beneficial. The oral care practice of ICU nurses ranged between average among $57 \%$ and poor among $23 \%$. The study highlighted the need for setting of ICU protocols and adoption of advanced training for ICU nurses.

\section{Keywords}

Oral Health, Intensive Care Unit, Nurses' Knowledge

\section{Introduction}

Quality of life and personal dignity have been reported to be affected by oral health. This impact appears to be more severe in medically compromised or hospitalized patients [1] [2]. Poor oral health or dysfunctions have a negative effect on nutritional status [3]-[5] and profound negative effects on general health.

Patients in the Intensive Care Units (ICU) have very specific care needs, demanding the highest standard of professional care [6]. They may be intubated, have a nasogastric tube in place, be heavily sedated, or febrile, all

${ }^{*}$ Corresponding author. 
of which may lead to dehydration and breathing through the mouth [7]. These, in turn, cause a change in oral flora and bacterial overgrowth, with the consequent loss of salivary effectiveness. Growth of potentially pathogenic bacteria in dental plaque provides a nidus of infection for microorganisms that can cause ventilator associated pneumonia (VAP) [8].

VAP is defined as pneumonia occurring in a patient who has been ventilated for at least 48 hours. It is the most common nosocomial infection and the leading cause of death in intensive care units (ICU) [8].

Its incidence varies from $9 \%$ to $28 \%$ with a mortality rate ranging from $24 \%$ to $50 \%$. These figures may be higher in immunocompromised patients and when the pneumonia is caused by multi-resistant pathogens [9].

Many barriers to providing effective oral health in ICU patients have been reported including low priority of oral care, fear of causing pain or injury to the patients, the perception that oral care does not provide significant health benefits, patients' resistive behaviors, inadequate nurse staffing, fear dislodging or displacing the tube, inducing bacteremia and lack of oral health related supplies [10].

These may partially account for the continuing low priority of oral care for patients in the ICU [11]. Additionally, oral hygiene performed by a nurse or aide is difficult, especially in patients who are semiconscious and non-cooperating [11].

The objective of this work is to describe the oral health knowledge, attitude and practice performed by ICU nurses and to study the factors affecting the quality of mouth care for ICU patients in governmental hospitals in Khartoum state. No previous studies in Sudan have assessed oral health knowledge, attitude and practice of ICU nurses towards their patients, and there was no formal unit protocol for the provision of oral care in the ICU.

\section{Material and Methods}

\subsection{Methods}

An observational, cross-sectional study in which an interview was randomly administered to 154 nurses in ICUs.

\subsection{Sample and Setting}

Study sites included ICUs in seven government hospitals in Khartoum state, Sudan. The total number of ICU nurses was 226. 154 nurses were randomly selected using formula of proportional estimate. All nurses were informed verbally about the study by the principal investigator, and signed a written consent to participate in the study.

\subsection{Ethical Considerations}

Ethical approvals were obtained from the Ministry of Health, the Clinical Research Centre from each hospital and University of Khartoum, Faculty of Dentistry Ethics Committee.

\subsection{Instruments}

The study was based on an interview which has been adopted from a survey that was conducted in Scotland (Rachel et al., 2009) with some modifications in the question of barriers to perform mouth care. A pilot study was carried out on a sample of ICU nurses to pretest the questionnaire and refine the questions in order to facilitate answering. The interview is composed of the following parts:

- Demographic data.

- ICU nurses knowledge about oral care.

- Attitudes of ICU nurses towards mouth care.

- ICU nurses mouth care practice.

- Barriers to perform oral care.

After completing the interview, the answered questions of knowledge, attitude, and practice were evaluated and scored.

\subsection{Data Collection}

Data collection was undertaken over 7 weeks in 2012. All nurses were informed verbally and in writing about the study, and that their participation was voluntary and anonymous. 


\subsection{Data Analysis}

Data were analyzed using the Statistical Package for Social Sciences (SPSS) 19.0.9 Standard Version (SPSS Inc., Chicago, IL, USA).

Demographic data, frequency distribution of oral care, types of materials used, and tools used were analyzed using descriptive statistics.

The correlation relationships between these three main variables (knowledge, attitude and practice) were determined. Then, relationships between variables such as educational level, experience in ICU with mean score of variables of knowledge, attitude, and practice were determined.

After two weeks from the first interview $10 \%$ of the questionnaires were re-distributed to the same participants for reliability check, and the kappa for the questionnaire ranged from ( 0.65 to 0.85$)$ except for the question of frequency of mouth care it was 0.37 .

\section{Results}

\subsection{Socio-Demographic Profiles for ICU Nurses}

Females outnumbered males (5 times), most nurses are holders of a Bachelor of Nursing degree, and the highest frequency in the shift pattern was the morning shift (Table 1).

The mean age of nurses was $27.95 \pm 4.51$ years, the median of their working experience as nurse was 4 years, the median of their working experience in the ICU was 13 months and the ratio of nurse to bed was 3:1 per day.

\subsection{Knowledge}

The majority of nurses $97.4 \%$ stated that provision of oral care in ICU is important for infection prevention, while $1.3 \%$ of them related its importance to patient comfort, $1.3 \%$ did not know why mouth care is important for ICU patient.

\subsection{Attitude}

Nurses who had negative attitude towards mouth care for ICU patients were in the minority (2.6\%), while the majority (97.4\%) of ICU nurses perceived oral care as a high nursing priority.

\subsection{Oral Care Practice}

Both type and frequency of oral care provision rose among the participants of this study. Most of the nurses reported that they performed mouth care twice daily (61\%), and the most frequent duration was $2-4$ minutes in (81.8\%) of the participants. Gauze and tongue depressors were the main tools used (Table 2).

Saline, lubricant, and mouth wash were the most commonly used materials.

Table 1. Gender, education, and shift pattern of ICU nurses.

\begin{tabular}{|c|c|c|c|}
\hline \multicolumn{2}{|c|}{ Variable } & \multirow{2}{*}{$\begin{array}{c}\text { Frequency } \\
25\end{array}$} & \multirow{2}{*}{$\begin{array}{l}\text { Percent } \\
16.2 \%\end{array}$} \\
\hline & Male & & \\
\hline & Female & 129 & $83.8 \%$ \\
\hline \multirow{3}{*}{ 2) Education } & Diploma & 24 & $15.6 \%$ \\
\hline & Bachelor's & 128 & $83.1 \%$ \\
\hline & Master & 2 & $1.9 \%$ \\
\hline \multirow{3}{*}{ 3) Shift pattern } & Morning & 95 & $61.7 \%$ \\
\hline & Afternoon night & 56 & $36.4 \%$ \\
\hline & Rotation & 2 & $1.9 \%$ \\
\hline
\end{tabular}


Table 2. Oral care practice.

\begin{tabular}{|c|c|c|}
\hline Variable & Frequency & Percent \\
\hline \multicolumn{3}{|l|}{ 1) Frequency of MC per day } \\
\hline Not at all & 0 & $0 \%$ \\
\hline Once per day & 43 & $27.9 \%$ \\
\hline Twice & 94 & $61.0 \%$ \\
\hline Three times & 8 & $5.2 \%$ \\
\hline More than three times & 9 & $5.8 \%$ \\
\hline \multicolumn{3}{|l|}{ 2) How long it last } \\
\hline Less than 1 min & 3 & $1.9 \%$ \\
\hline Between 1 - 5 min & 126 & $81.8 \%$ \\
\hline Between 5 - 10 min & 25 & $16.2 \%$ \\
\hline \multicolumn{3}{|l|}{ 3) Tools } \\
\hline Adult tooth brush & 0 & $0 \%$ \\
\hline Pediatric tooth brush & 0 & $0 \%$ \\
\hline Electric tooth brush & 0 & $0 \%$ \\
\hline Foam swab & 2 & $1.3 \%$ \\
\hline Gauze + tongue depressor & 152 & $98.7 \%$ \\
\hline \multicolumn{3}{|l|}{ 4) Which part of the mouth } \\
\hline Brushing of teeth & 0 & $0 \%$ \\
\hline Brushing of gum & 0 & $0 \%$ \\
\hline Brushing of tongue & 0 & $0 \%$ \\
\hline All & 154 & $100 \%$ \\
\hline
\end{tabular}

\subsection{Relationships between Oral Care Knowledge, Attitude, and Practice for ICU Nurses}

There was a highly significant correlation $(\mathrm{P}<0.000)$ between knowledge and attitude. Insignificant correlations were found between knowledge and practice $(\mathrm{P}<0.192)$, and attitude and practice $(\mathrm{P}<0.097)$. The ranking of knowledge, attitude, and practice of ICU nurses with respect to education level (Table 3) demonstrated that:

High knowledge (91.6\% - 100\%), and positive attitude $(91.7 \%-100 \%)$ were scored, and these scores increased with increase in educational level of nurses. However, the majority of diploma holders practice was poor and the majority of bachelor holders practice was average. Data on knowledge, attitude, and practice in relation to duration of experience (Figure 1, Figure 2) revealed that experience has led to great improvement in knowledge and positive attitude.

\subsection{Constraints to Perform Mouth Care}

Most of ICU nurses (67.3\%) found no difficulties in performing mouth care for their patients. Barriers for ICU nurses could be uncooperative patient (13\%), inadequate staff (9.7\%), fear of tube displacement $(9.1 \%)$, lack of oral care requisites (7.8\%), unpleasant task (4.5\%) and lack of knowledge (1.9\%).

Logistic regression analysis showed (Table 4):

1) Bachelor degree holders are more likely to adopt good practice than the diploma holders by 6.1 times.

2) The ICU nurses reported that in the presence of hospital equipments their good oral care practice will increase by 4.4 times.

3) The ICU nurses reported that if they had received training their practice will improve by 3.5 times. 
Table 3. Knowledge, attitude and practice of ICU nurses with different educational level.

\begin{tabular}{|c|c|c|c|c|c|c|c|c|}
\hline \multirow{2}{*}{$\begin{array}{l}\text { Level of } \\
\text { education }\end{array}$} & \multicolumn{3}{|c|}{ Knowledge } & \multicolumn{2}{|c|}{ Attitude } & \multicolumn{3}{|c|}{ Practice } \\
\hline & High & Average & Low & Positive & Negative & Good & Average & Poor \\
\hline Diploma & $\begin{array}{c}22 \\
91.6 \%\end{array}$ & $\begin{array}{c}0 \\
0 \%\end{array}$ & $\begin{array}{c}2 \\
8.3 \%\end{array}$ & $\begin{array}{c}22 \\
91.7 \%\end{array}$ & $\begin{array}{c}2 \\
8.3 \%\end{array}$ & $\begin{array}{c}4 \\
16.7 \%\end{array}$ & $\begin{array}{c}9 \\
37.5 \%\end{array}$ & $\begin{array}{c}11 \\
45.8 \%\end{array}$ \\
\hline Bachelors & $\begin{array}{c}126 \\
98.4 \%\end{array}$ & $\begin{array}{c}2 \\
1.6 \%\end{array}$ & $\begin{array}{c}0 \\
0 \%\end{array}$ & $\begin{array}{c}126 \\
98.4\end{array}$ & $\begin{array}{c}2 \\
1.6 \%\end{array}$ & $\begin{array}{c}25 \\
19.5 \%\end{array}$ & $\begin{array}{c}78 \\
60.9 \%\end{array}$ & $\begin{array}{c}25 \\
19.5 \%\end{array}$ \\
\hline Master & $\begin{array}{c}2 \\
100 \%\end{array}$ & $\begin{array}{c}0 \\
0 \%\end{array}$ & $\begin{array}{c}0 \\
0 \%\end{array}$ & $\begin{array}{c}2 \\
100 \%\end{array}$ & $\begin{array}{c}0 \\
0 \%\end{array}$ & $\begin{array}{c}1 \\
50 \%\end{array}$ & $\begin{array}{c}1 \\
50 \%\end{array}$ & $\begin{array}{c}0 \\
0 \%\end{array}$ \\
\hline
\end{tabular}

Table 4. Multiple regression analysis of oral care practice and different variables.

\begin{tabular}{|c|c|c|c|c|}
\hline Variable & $\mathrm{P}$ & Bivariate & $\mathrm{P}$ & Multivariate \\
\hline \multicolumn{5}{|l|}{ Gender } \\
\hline $\begin{array}{c}\text { Male } \\
\text { Female }\end{array}$ & 0.01 & $\begin{array}{c}1 \\
3.26(1.33-8.058)\end{array}$ & 0.11 & \\
\hline \multicolumn{5}{|l|}{ Experience } \\
\hline $\begin{array}{l}\text { Less than one year } \\
\text { More than two year }\end{array}$ & 0.663 & $\begin{array}{c}1 \\
1.25(0.048-3.24)\end{array}$ & 0.644 & \\
\hline \multicolumn{5}{|l|}{ Education } \\
\hline $\begin{array}{l}\text { Diploma } \\
\text { Bachelor }\end{array}$ & 0.007 & $\begin{array}{c}1 \\
3.49(1.39-8.69)\end{array}$ & 0.009 & $6.1(1.58-23.56)$ \\
\hline \multicolumn{5}{|l|}{ Knowledge } \\
\hline $\begin{array}{l}\text { Low } \\
\text { High }\end{array}$ & 0.99 & $5.018(0.00-0.00)$ & 1.000 & \\
\hline \multicolumn{5}{|l|}{ Attitude } \\
\hline $\begin{array}{l}\text { Negative } \\
\text { Positive }\end{array}$ & 0.99 & $\begin{array}{c}1 \\
0.00\end{array}$ & 1.000 & \\
\hline \multicolumn{5}{|l|}{ Hospital equipment } \\
\hline $\begin{array}{l}\text { No } \\
\text { yes }\end{array}$ & 0.05 & $\begin{array}{c}1 \\
2.71(0.97-7.55)\end{array}$ & 0.017 & $4.7(1.32$ - 16.49) \\
\hline \multicolumn{5}{|l|}{ Uncooperative patient } \\
\hline $\begin{array}{l}\text { No } \\
\text { Yes }\end{array}$ & 0.34 & $\begin{array}{c}1 \\
1.85(0.51-6.71)\end{array}$ & 0.164 & \\
\hline \multicolumn{5}{|l|}{ Inadequate staff } \\
\hline $\begin{array}{l}\text { No } \\
\text { Yes }\end{array}$ & 0.75 & $\begin{array}{c}1 \\
1.24(0.33-4.68)\end{array}$ & 0.862 & \\
\hline \multicolumn{5}{|l|}{ Unpleasant task } \\
\hline $\begin{array}{l}\text { No } \\
\text { Yes }\end{array}$ & 0.74 & $\begin{array}{c}1 \\
0.75(0.140-4.05)\end{array}$ & 0.344 & \\
\hline \multicolumn{5}{|l|}{ Tube displacement } \\
\hline $\begin{array}{l}\text { No } \\
\text { Yes }\end{array}$ & 0.08 & $\begin{array}{c}1 \\
0.36(0.12-1.13)\end{array}$ & 0.537 & \\
\hline \multicolumn{5}{|l|}{ Training } \\
\hline $\begin{array}{l}\text { Not received } \\
\text { Received }\end{array}$ & 0.001 & $3.52(1.62-7.65)$ & 0.008 & $3.5(1.38-8.85)$ \\
\hline \multicolumn{5}{|l|}{ No barriers } \\
\hline $\begin{array}{l}\text { No } \\
\text { yes }\end{array}$ & 0.36 & $1.43(0.65-3.11)$ & 0.176 & \\
\hline Constant & & 0.000 & 1.000 & \\
\hline
\end{tabular}




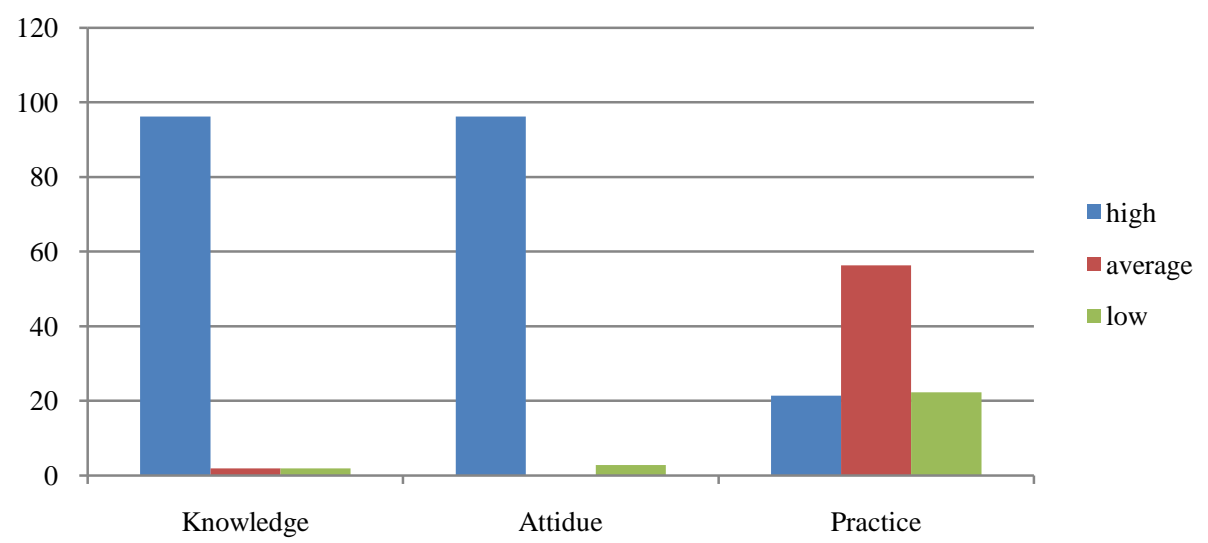

Figure 1. The percentage of knowledge, attitude, and practice of nurses' experience less than 12 months.

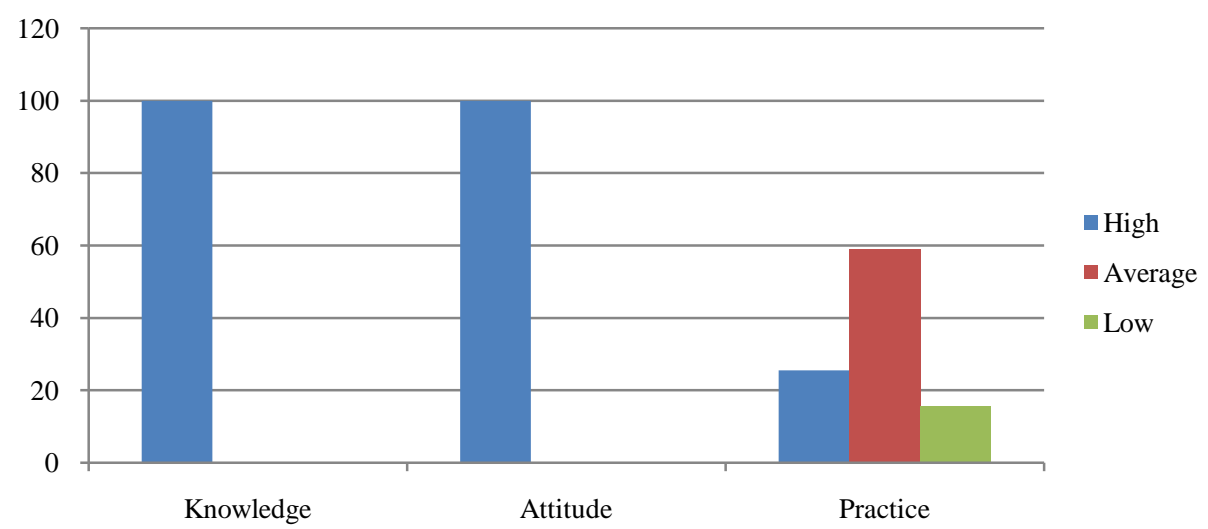

Figure 2. The percentage of knowledge, attitude, and practice of nurses' experience more than 12 months.

\section{Discussion}

The two thirds of nurses who have received training indicated that $92 \%$ of their training was part of basic nursing training. This could be problematic, as oral care for an intubated patient requires different knowledge and skills compared to that for a ward patient. In South Africa [12] basic nursing training was the only source of training for 35 nurses (36.5\%), whereas 22 nurses (22.9\%) had received training while completing their postgraduate programme. Two nurses (2.1\%) stated that their only source of training had been during continuing education activities such as congress attendance, and 10 nurses (10.4\%) indicated that their primary source of education had been hospital in-service.

In England [13] most nurses had received training during their initial nursing course (42, 41\%) and/or whilst "on the job" $(50,48.5 \%)$ and a minority had attended a later training course in oral care $(15,14.5 \%)$. Sixty-one (59\%) nurses did not recall receiving any oral care instruction during their initial training period.

In all ICUs studies, there was no formal unit's protocol for assessment or provision of oral care for ICU patients, and this may influence nurses' practice. This is, in contrast, with the Scottish survey [14] where most units $(n=21,88 \%)$ assessed the patient's oral care needs within 24 hours of admission and seven units (29\%) had set protocol for this assessment. While in UK, 11 (46\%) of the result of the assessment was recorded in the nursing record. Only 27 (26\%) nurses used a written assessment tool or protocol [13].

The average mouth care frequency of practice of twice per day (61\%), was lower than that of five times practiced by $72 \%$ of nurses in USA [15], while in Scotland oral care was performed more than three times per day by 24 nurses (100\%) [14].

The present study showed that the use of gauze and tongue depressor (98.7\%) to perform mouth care, surpassed that was reported in Israel (55\%) [16]. While in UK tooth brushes were used at least once a day by 88 
(85.5\%) nurses with 9 (8.5\%) nurses stating that they had never used tooth brushes.

The material used for mouth care differs within and between countries. In Sudan it was found that saline is used by (98.1\%) of the nurses and mouth wash by (29.2\%) of them, while in Israel mouth wash was used by $75 \%$ of the nurses [19]. Chlorhexidine products were routinely used by 58.5\% in UK [13] and 81.9\% in USA [15].

The general trend of correlation between educational level and ICU nurses' knowledge and practice revealed in this study is similar to USA. While in Taiwan there was no significant correlation between the total scores on knowledge and attitudes about oral care and the nurses' educational level, the type of ICU they worked in, years of experience working in an ICU or years of experience working at their present ICU [17].

The finding that no significant correlation between ICU nurses experience and their knowledge, attitude and practice towards mouth care was in contrast with European countries [18], where the more experienced the nurses, the more knowledge, attitude, and practice of oral care is performed to prevent VAP [18]. In Taiwan, also, there was a significant correlation between the age of the nurses and their total score on oral care practices [17].

In the present study the most frequent constraint to perform mouth care was uncooperativeness of the patients (13\%), unlike in USA where this was attributed to inadequate staff [19]-[21].

Regarding hospital equipments, $72 \%$ of nurses agreed that the availability of hospital equipments and supplies were unsatisfactory. In UK, hospital factors were found to affect the type and quality of oral care given by nurses [22].

A potential bias in our survey is that all the nurses were from university or academic institutions. The survey carried out by Binkley in USA [23] found that private hospitals provided more oral care than university-affiliated centers.

As this study was carried out in seven government hospitals, its findings could not be generalized to all the hospitals in Sudan, yet the findings can possibly be taken as indicators.

\section{Conclusion}

The oral care practice of ICU nurses ranged between average among $57 \%$ and poor among $23 \%$ of the nurses who participated in this study. Two thirds of the nurses' oral care training was acquired during their basic nursing education. The most frequent barrier to perform mouth care was uncooperativeness of the patients and the least frequent barrier was lack of knowledge. The study highlighted the need for setting of ICU protocols and adoption of advanced training for ICU nurses.

\section{References}

[1] Allen Furr, L., Catherine, J.B., Cynthia, M. and Ruth, C. (2004) Factors Affecting Quality of Oral Care in Intensive Care Units. Journal of Advanced Nursing, 48, 454-462. http://dx.doi.org/10.1111/j.1365-2648.2004.03228.x

[2] Cindy, L. and Grap, M.J. (2004) Oral Health and Care in the Intensive Care Unit: State of Science. American Journal for Critical Care, 13, 25-34.

[3] Gipe, B., Donnelly, D. and Harris, S. (1995) A Survey of Dental Health in Patients with Respiratory Failure. American Journal Respiratory Critical Care, 151, A340.

[4] Renée, G., Daniel, G. and Léo, F. (2000) The Oral Cavity as a Reservoir of Bacterial Pathogens for Focal Infections. Microbes and Infection, 2, 897-906. http://dx.doi.org/10.1016/S1286-4579(00)00391-9

[5] Lockhart, P.B. and Durack, D.T. (1999) Oral Micro Flora as a Cause of Endocarditis and Other Distant Site Infections. Infectious Disease Clinics of North America, 13, 833-850. http://dx.doi.org/10.1016/S0891-5520(05)70111-2

[6] Loesche, W.L. (1997) Association of the Oral Flora with Important Medical Diseases. Current Opinion in Periodontology, 4, 21-28.

[7] Li, X.J., Kolltveit, K.M., Tronstad, L. and Olsen, I. (2000) Systemic Diseases Caused by Oral Infection. Clinical Microbiology, 13, 547-558. http://dx.doi.org/10.1128/cmr.13.4.547-558.2000

[8] Scannapieco, F.A. and Alex, W.H. (2001) Potential Associations between Chronic Respiratory Disease and Periodontal Disease. Journal of Periodontology, 72, 50-56. http://dx.doi.org/10.1902/jop.2001.72.1.50

[9] Scannapieco, F.A. (1999) Role of Oral Bacteria in Respiratory Infection. Journal of Periodontology, 70, 793-802. http://dx.doi.org/10.1902/jop.1999.70.7.793

[10] Garrouste-Ortegas, S., Chevret, G., Arlet, O., Marie, M., Rouveau, M., Popoff, N. and Schlemmer, B. (1997) Oropharyngeal or Gastric Colonization and Nosocomial Pneumonia in Adult Intensive Care Unit Patients. American Journal 
for Respiratory Critical Care, 156, 1647-1655. http://dx.doi.org/10.1164/ajrccm.156.5.96-04076

[11] Scannapieco, F.A., Stewart, E.M. and Mylotte, J.M. (1992) Colonization of Dental Plaque by Respiratory Pathogens in Medical Intensive Care Patients. Critical Care Medicine, 20, 740-745. http://dx.doi.org/10.1097/00003246-199206000-00007

[12] Juan, S., Helen, P. and Sonja, W. (2011) A Survey of Oral Care Practices in South African Intensive Care Units. SAJCC, 27, 42-46.

[13] Jones, H., Newton, J. and Bower, E. (2004) A Survey of the Oral Care Practices of Intensive Care Nurses. Intensive and Critical Care Nursing, 20, 69-76. http://dx.doi.org/10.1016/j.iccn.2004.01.004

[14] Rachel, K., Andrew, B. and Malcom, B. (2009) Oral Hygiene Practices in Scottish Intensive Care Units-A National Survey the Intensive Care Society. Journal of the Intensive Care Society, 10, 155-157.

[15] Grap, M.J., Munro, C., Ashtiani, B. and Bryant, S. (2003) Oral Care Interventions in Critical Care. American Journal of Critical Care, 12, 113-119.

[16] Ferda, G., Naomi, F., Ofra, R., Miriam, A., Madline, B., Maureen, B. and Julie, B. (2009) ICU Nurses’ Oral-Care Practices and the Current Best Evidence. Journal of Nursing Scholarship, 41, 132-138. http://dx.doi.org/10.1111/j.1547-5069.2009.01264.X

[17] Lin, Y.-S., Chang, J.-C., Chang, T.-H. and Lou, M.-F. (2011) Critical Care Nurses’ Knowledge, Attitudes and Practices of Oral Care for Patients with Oral Endotracheal Intubation: A Questionnaire Survey. Journal of Clinical Nursing, 20, 3204-3214. http://dx.doi.org/10.1111/j.1365-2702.2011.03819.x

[18] Labeau, S., Vandijck, D., Rello, J., Adam, S., Rosa, A., Wenisch, C., Bäckman, C., Agbaht, K., Csomos, A., Seha, M., Dimopoulos, G., Vandewoude, K.H. and Blot, S. (2008) Evidence-Based Guidelines for the Prevention of VentilatorAssociated Pneumonia: Results of a Knowledge Test among European Intensive Care Nurses. Journal of Hospital Infection, 70, 180-185. http://dx.doi.org/10.1016/j.jhin.2008.06.027

[19] Aiken, L.H., Clarke, S.P., Sloane, D.M., Sochalski, J. and Silber, J.H. (2002) Hospital Nurse Staffing and Patient Mortality, Nurse Burnout, and Job Dissatisfaction. Journal of the American Medical Association, 288, 1987-1993. http://dx.doi.org/10.1001/jama.288.16.1987

[20] Steinbrook, R. (2002) Nursing in the Crossfire. New England Journal of Medicine, 346, 1756-1766. http://dx.doi.org/10.1056/NEJM200205303462225

[21] Louis, F., Rose, B.M., Walter, C. and Brian, L.M. (2002) Oral Care for Patients with Cardiovascular Disease and Stroke. Journal of the American Dental Association, 133, 37S-44S.

[22] Buerhaus, P.I., Staiger, D.O. and Auerbach, D.I. (2000) Why Are Shortages of Hospital RNs Concentrated in Specialty Care Units. Nursing Economics, 19, 1-6.

[23] Binkley, C., Furr, L., Carrico, R. and McCurren, C. (2004) Survey of Oral Care Practices in US Intensive Care Units. American Journal of Infection Control, 32, 161-169. http://dx.doi.org/10.1016/j.ajic.2003.05.001 